\title{
Efficacy and toxicity of histone deacetylase inhibitors in relapsed/refractory multiple myeloma: Systematic review and meta-analysis of clinical trials
}

\author{
XIAO GAO, LIJING SHEN, XIANG LI and JIAYING LIU \\ Department of Hematology, Renji Hospital, School of Medicine, Shanghai Jiaotong University, Shanghai 200127, P.R. China
}

Received September 10, 2018; Accepted April 24, 2019

DOI: $10.3892 /$ etm.2019.7704

\begin{abstract}
Multiple myeloma (MM) remains incurable primarily due to relapse. Histone deacetylase inhibitors (HDACis) have shown potential application for the treatment of relapsed/refractory multiple myeloma (RRMM). To assess the efficacy and safety of HDACis in RRMM treatment, a systematic review and meta-analysis were conducted based on clinical trial data. A literature search was performed using PubMed, EMBASE, Web of Science and the Cochrane Library databases. Subsequently, 19 trials with 2193 patients treated with one of the three HDACis, panobinostat, ricolinostat and vorinostat, were identified and included in the present study. The efficacy and toxicity of each agent were assessed. The data were pooled using a random effects model in STATA 13.0. The results showed that the overall response rate (ORR) was 0.64 with a $95 \%$ confidence interval (CI) of $0.61-0.68$ for panobinostat, 0.51 (95\% CI, 0.46-0.55) for vorinostat and 0.38 (95\% CI, 0.29-0.48) for ricolinostat. Additionally, subgroup analysis revealed an ORR of 0.36 (95\% CI, 0.27-0.46) for HDACis-treated bortezomib-refractory MM patients and 0.43 (95\% CI, 0.30-0.55) for lenalidomide-refractory patients. The most common grade 3 and 4 hematological adverse events were thrombocytopenia, neutropenia and anemia. Non-hematological adverse events included fatigue/asthenia, diarrhea and nausea. In conclusion, analysis of the pooled data revealed that panobinostat-containing regimens were effective and tolerable for patients with RRMM. Furthermore, lenalidomide-refractory patients may derive greater benefits from these regimens. More clinical and real-world studies are required to validate these results.
\end{abstract}

Correspondence to: Dr Lijing Shen, Department of Hematology, Renji Hospital, School of Medicine, Shanghai Jiaotong University, 160 Pujian Road, Shanghai 200127, P.R. China

E-mail: slj_tch@163.com

Key words: multiple myeloma, histone deacetylase inhibitors, systematic review, meta-analysis

\section{Introduction}

Multiple myeloma (MM), a malignant disease of plasma cells, is one of three major hematological malignancies with the second highest incidence rate (1). MM mostly occurs in older patients (2) and is characterized by high monoclonal immunoglobulin (also called M protein), and is often accompanied by hypercalcemia, anemia, bone and renal damage (3).

Over the past two decades, there have been new approved treatment strategies for patients with MM, including bortezomib, thalidomide or lenalidomide-containing standard regimens, which have improved the survival of patients with MM (4). However, most patients relapse after several lines of therapy, resulting in poor clinical response and survival outcomes (5). Therefore, there is an urgent need for more effective therapeutic strategies for patients with relapsed/refractory multiple myeloma (RRMM).

Histone deacetylase inhibitors (HDACis) have demonstrated antitumor activity in other hematological malignancies. For example, the HDACi vorinostat was initially approved by the US Food and Drug Administration (FDA) for the treatment of cutaneous T-cell lymphoma in 2009 (6). MM cells have an abnormal acetylated spectrum (7), which provides new insights into the application of HDACis to the treatment of MM. Basic studies have demonstrated the anti-MM activity of HDACis, which can induce apoptosis and cell cycle arrest, and degrade unfolded protein by the aggresome pathway in concert with the ubiquitin-proteasome system (8-10). Additionally, panobinostat was approved by the FDA for RRMM therapy in 2015 following the PANORAMA 2 randomized clinical trial (11). Currently, there are a number of HDACis undergoing clinical testing (12). The aim of the present study was to perform a meta-analysis to evaluate the efficacy and safety of HDACis in patients with RRMM. Additionally, a subgroup analysis was performed of patients who were bortezomib-refractory and lenalidomide-refractory to identify which patients may benefit more from the application of HDACis.

\section{Materials and methods}

Search strategies. Databases, including PubMed, EMBASE, Web of Science and the Cochrane Library were searched for clinical trials including phase I, II and III trials published between Jan 2009 and March 2018, without any language 


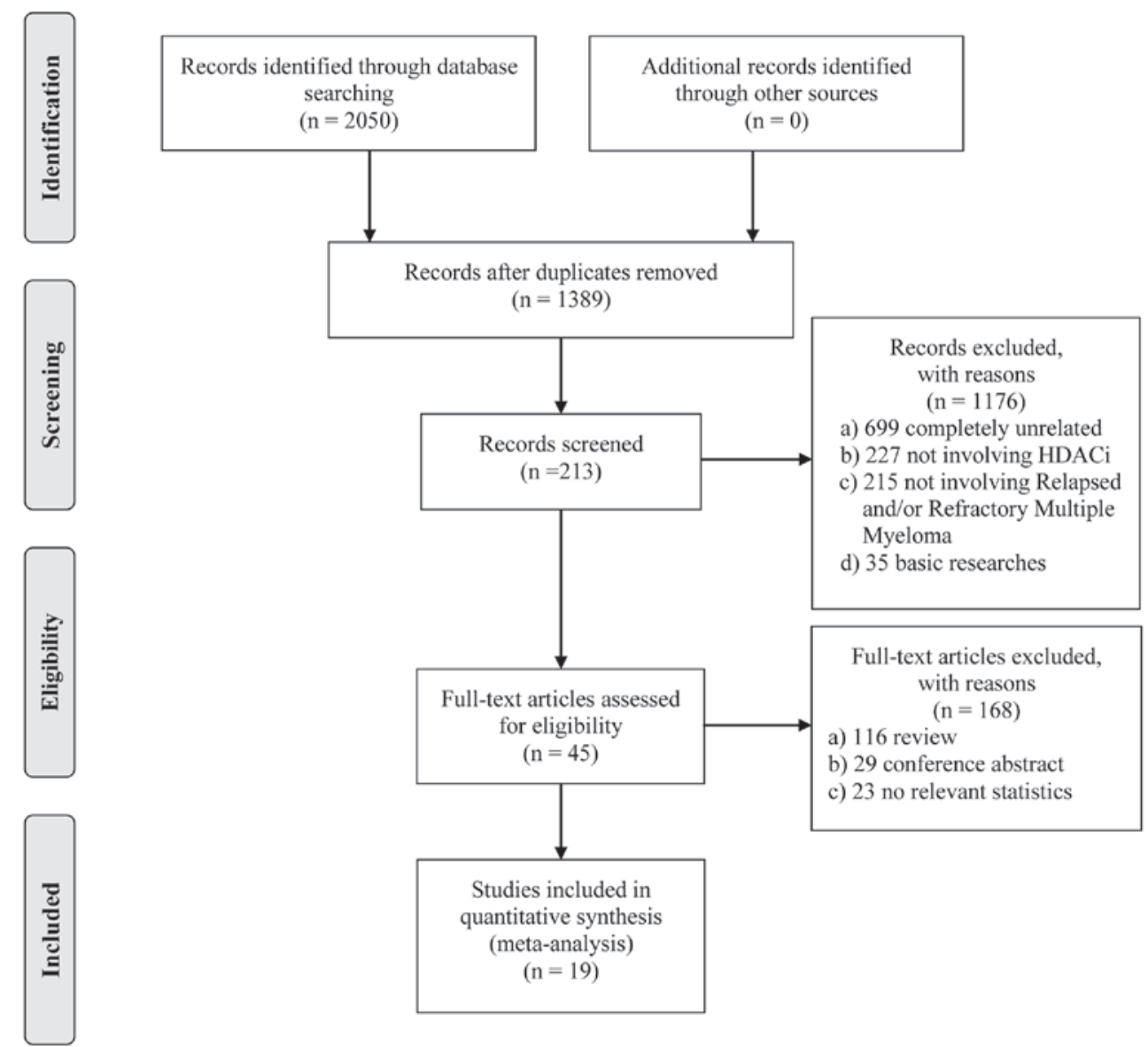

Figure 1. Flow diagram of study workflow. Basic researches, experimental research on cell lines or animals; completely unrelated, the retrieved research topic is not relevant to the present research.

restrictions. Our search criteria were based on combinations of the following keywords: 'Relapsed', 'refractory', 'multiple myeloma' and 'histone deacetylase inhibitor'.

Eligibility criteria. The eligibility criteria included: i) Patients with RRMM and intent-to-treat individuals in the studies were $\geq 10$; ii) treatment with an HDACi, including vorinostat, panobinostat, ricolinostat; iii) the studies provided overall response rate (ORR) and/or overall survival (OS) and/or progression-free survival (PFS), as well as adverse event data which allowed statistical analysis to be performed. Additional relevant references listed in other reviews and guidelines which met all the criteria of the present study were also identified. Studies based on animal or cell line data, case reports, conference abstracts or restricted access studies were excluded.

Data extraction. Data were independently extracted by two investigators (XG and $\mathrm{XL}$ ). Any discrepancies between the two investigators were solved by a third author (JL). The following data were extracted from all included publications and exported manually to Microsoft Excel 2016. Study name, year, therapy regimens, country, number of included patients, prior treatment lines and regimens, best response and grade 3 and 4 adverse events including anemia, neutropenia, thrombocytopenia, fatigue/asthenia, diarrhea and nausea were recorded. Adverse affects were assessed in accordance with the Common Terminology Criteria for Adverse Events version 3.0 (13) and were classed as: Grade 1, mild; grade 2, moderate; grade 3, severe; grade 4, life-threatening; grade 5, death. As the literature provided more information regarding stages 3 and 4 , these were selected for examination in the current study.

Statistical analysis. A random effects model was chosen to account for the heterogeneity between the selected studies. STATA version 13.0 (StataCorp LP) was used to conduct statistical analysis. $\mathrm{P}<0.05$ was considered to indicate a statistically significant difference. Heterogeneity was evaluated by $\mathrm{I}^{2}$ value, and significant heterogeneity was defined as $\mathrm{I}^{2}>50 \%$.

\section{Results}

Literature search. In total, 213 potentially relevant studies were screened after the removal of redundant duplicates and irrelevant studies. Among the remaining articles, 168 reports were further excluded as most of them were reviews, conference abstracts or had no reported data. Following this, 45 full-text articles were evaluated in detail. Fourteen of these studies did not provide accessible data, 10 were updates for previously published data, and one study had a sample size of $<10$ patients. Ultimately, 19 papers met the selection criteria and were included in the meta-analysis. The flow diagram of the study design based on PRISMA 2009 (14) is presented in Fig. 1. 
Table I. Baseline of 19 studies included in the present meta-analysis.

A, Panobinostat

\begin{tabular}{|c|c|c|c|c|c|c|c|c|}
\hline Study & Year & Country & Phase & Regimen & $\begin{array}{c}\text { Patients, } \\
\mathrm{n}\end{array}$ & $\begin{array}{c}\text { Dosage of } \\
\mathrm{HDACi}, \mathrm{mg}\end{array}$ & $\begin{array}{l}\text { Median age, } \\
\text { years (range) }\end{array}$ & (Refs.) \\
\hline Isoda et al & 2018 & Japan & I & PanVd & 10 & $10 / 15 / 20$ & $66(53-77)$ & (26) \\
\hline Popat et al & 2016 & UK & $\mathrm{I} / \mathrm{II}$ & PanVTd & 46 & $10 / 15 / 20$ & $61(51-66)$ & (22) \\
\hline San-Miguel et al & 2013 & US & $\mathrm{Ib}$ & PanV & 62 & $10 / 20 / 25 / 30$ & $62(46-83)$ & (30) \\
\hline Offidani et al & 2012 & Italy & II & PanMTd & $\begin{array}{l}12 \\
19\end{array}$ & $\begin{array}{l}15 \\
10\end{array}$ & $\begin{array}{l}73(49-81) \\
65(40-78)\end{array}$ & (20) \\
\hline Berdeja et al & 2015 & US & $\mathrm{I} / \mathrm{II}$ & PanK & 44 & $20 / 30$ & $66(41-82)$ & (23) \\
\hline Berenson et al & 2014 & US & $\mathrm{I} / \mathrm{II}$ & PanM & 40 & $15 / 20$ & $65(34-88)$ & (24) \\
\hline Richardson et al & 2013 & US & $\mathrm{I} / \mathrm{II}$ & PanVd & 55 & 20 & $61(41-88)$ & $(25)$ \\
\hline Wolf et al & 2012 & US & II & Pan & 38 & 20 & $61(43-72)$ & (19) \\
\hline Baertsch et al & 2018 & Ger & Real-world & PanVd & 24 & 20 & $67(49-87)$ & (15) \\
\hline San-Miguel et al & 2014 & US & III & $\begin{array}{l}\text { PanVd } \\
\text { PboVd }\end{array}$ & $\begin{array}{l}387 \\
381\end{array}$ & $\begin{array}{c}20 \\
-\end{array}$ & $\begin{array}{l}63(56-69) \\
63(56-68)\end{array}$ & (11) \\
\hline Chari et al & 2017 & US & II & PanRd & 27 & 20 & $64(51-75)$ & (18) \\
\hline
\end{tabular}

B, Vorinostat

\begin{tabular}{|c|c|c|c|c|c|c|c|c|}
\hline Study & Year & Country & Phase & Regimen & $\begin{array}{c}\text { Patients, } \\
\mathrm{n}\end{array}$ & $\begin{array}{c}\text { Dosage of } \\
\text { HDACi, mg }\end{array}$ & $\begin{array}{l}\text { Median age, } \\
\text { years (range) }\end{array}$ & (Refs.) \\
\hline Sanchez et al & 2016 & US & $\mathrm{IIb}$ & VorRd & 25 & 400 & $65(48-82)$ & (17) \\
\hline Vesole et al & 2015 & US & I & VorKRd & 17 & $300 / 400$ & $61(48-71)$ & (29) \\
\hline Voorhees et al & 2017 & US & I & VorVPLD & 32 & $200 / 300 / 400$ & $61(39-75)$ & (27) \\
\hline Weber et al & 2012 & US & I & VorV & 34 & $200 / 300 / 400$ & $61(45-79)$ & $(31)$ \\
\hline \multirow[t]{2}{*}{ Dimopoulos et al } & 2013 & US & III & VorV & 317 & 400 & $61(30-85)$ & (16) \\
\hline & & & & $\mathrm{PboV}$ & 320 & - & $63(29-86)$ & \\
\hline Badros et al & 2009 & US & I & VorV & 23 & $100 / 200 / 400 / 500$ & $54(39-78)$ & (32) \\
\hline \multicolumn{9}{|l|}{ C, Ricolinostat } \\
\hline \multirow[t]{4}{*}{ Vogl et al } & 2017 & US & $\mathrm{I} / \mathrm{II}$ & Rico & 15 & $40 / 80 / 160 / 240 / 360$ & $70(51-79)$ & $(21)$ \\
\hline & & & & RicoVd & 57 & $40 / 80 / 160 / 240 / 360$ & $65(47-84)$ & \\
\hline & & & & RicoVd & 20 & $\geq 160$ & $65(47-83)$ & \\
\hline & & & & RicoVd & 24 & 160 & $67(48-84)$ & \\
\hline Yee et al & 2016 & US & $\mathrm{Ib}$ & RicoRd & 38 & $40 / 80 / 160 / 240$ & $63(57-71)$ & (28) \\
\hline
\end{tabular}

Pan, panobinostat; V, bortezomib; d, dexamethasone; T, thalidomide; Rico, ricolinostat; R, lenalidomide; Vor, vorinostat; K, carfilzomib; PLD, pegylated-liposomal doxorubicin; M, melphalan; Ger, Germany; Pbo, placebo; -, no HDACi was administered in the placebo group.

Study characteristics. A total of 19 clinical trials with 2,193 evaluable participants treated with one of three HDACis (panobinostat, ricolinostat and vorinostat) were included in the present study. In terms of study design, there was one real-world study (15), 2 phase III studies (11,16), 4 phase II studies (17-20), 5 phase I/II studies (21-25) and 7 phase I studies (26-32). Baseline information of the included study characteristics and prior therapies are presented in Tables I and II.

Response to HDACi treatment. The extracted data were categorized into three groups in order to assess clinical efficacy based on treatment with panobinostat, ricolinostat and vorinostat. Raw data on the effectiveness of the treatment are presented in Table III, including ORR, complete response, very good partial response, partial response, median PFS, median OS and median follow-up. Analysis of the pooled data demonstrated that ORR was 0.64 (95\% confidence interval $[\mathrm{CI}], 0.61-0.68 ; \mathrm{I}^{2}, 91.5 \%$; $\left.\mathrm{P}<0.001\right)$ for $\mathrm{MM}$ patients treated with panobinostat, 0.51 (95\% CI, 0.46-0.55; $\left.\mathrm{I}^{2}, 81.3 \% ; \mathrm{P}<0.001\right)$ for those treated with vorinostat, and 0.38 (95\% CI, 0.29-0.48; $\mathrm{I}^{2}, 85.0 \%$; $\mathrm{P}=0.010$ ) for patients treated with ricolinostat. The results also revealed that the 
Table II. Prior treatments.

A, Panobinostat

\begin{tabular}{|c|c|c|c|c|c|c|}
\hline \multirow[b]{2}{*}{ Study } & \multirow[b]{2}{*}{ Year } & \multirow{2}{*}{$\begin{array}{c}\text { Median number of } \\
\text { prior therapies (range) }\end{array}$} & \multicolumn{2}{|c|}{ Prior regimens } & \multirow{2}{*}{$\begin{array}{c}\text { PIs and } \\
\text { iMIDs, n (\%) }\end{array}$} & \multirow[b]{2}{*}{ (Refs.) } \\
\hline & & & PIs, n (\%) & iMIDs, n (\%) & & \\
\hline Isoda et al & 2018 & $3.5(1-5)$ & - & - & - & (26) \\
\hline Popat et al & 2016 & $1(1-4)$ & $33(72)$ & $24(52)$ & $8(17)$ & (22) \\
\hline San-Miguel et al & 2013 & $2(1-10)$ & 39 (62.9) & $\begin{array}{l}\mathrm{T}: 28(45.2) \\
\mathrm{R}: 28(45.2)\end{array}$ & - & (30) \\
\hline Offidani et al & 2012 & - & $8(67)$ & $\begin{array}{l}\mathrm{T}: 7(58) \\
\mathrm{R}: 5(42)\end{array}$ & - & (20) \\
\hline Berdeja et al & 2015 & $5(1-10)$ & $39(89)$ & $39(89)$ & $35(80)$ & (23) \\
\hline Berenson et al & 2014 & $4(1-16)$ & $2(0-9)$ & - & - & (24) \\
\hline Richardson et al & 2013 & $4(2-11)$ & $55(100)$ & $\begin{array}{l}\mathrm{T}: 38(69.1) \\
\mathrm{R}: 54(98.2)\end{array}$ & - & $(25)$ \\
\hline Wolf et al & 2012 & $5(-)$ & $2(5.3)$ & $3(7.9)$ & $24(63.2)$ & (19) \\
\hline Baertsch et al & 2018 & $5(2-17)$ & $\begin{array}{l}V: 23(96) \\
K: 7(29)\end{array}$ & $\begin{array}{c}\text { R: } 23(96) \\
\text { Pom: } 16(67)\end{array}$ & & (15) \\
\hline $\begin{array}{l}\text { San-Miguel et al } \\
\text { (PANORAMA 1) }\end{array}$ & 2014 & $1(1-3)$ & $169(44)$ & $\begin{array}{l}\mathrm{R}: 72(19) \\
\mathrm{T}: 205(53)\end{array}$ & $94(24)$ & (11) \\
\hline Chari et al & 2017 & $3(1-10)$ & $\begin{array}{l}\text { V: } 27(100) \\
\text { K: } 8(30)\end{array}$ & $\begin{array}{c}\text { R: } 27(100) \\
\text { T: } 6(22) \\
\text { Pom: } 10(37)\end{array}$ & - & (18) \\
\hline
\end{tabular}

B, Vorinostat

\begin{tabular}{|c|c|c|c|c|c|c|}
\hline \multirow[b]{2}{*}{ Study } & \multirow[b]{2}{*}{ Year } & \multirow{2}{*}{$\begin{array}{c}\text { Median number of } \\
\text { prior therapies (range) }\end{array}$} & \multicolumn{2}{|c|}{ Prior regimens } & \multirow{2}{*}{$\begin{array}{c}\text { PIs and } \\
\text { iMIDs, n (\%) }\end{array}$} & \multirow[b]{2}{*}{ (Refs.) } \\
\hline & & & PIs, n (\%) & iMIDs, n (\%) & & \\
\hline Sanchez et al & 2016 & - & $20(80)$ & $9(36)$ & - & (17) \\
\hline Vesole et al & 2015 & $4(1-9)$ & $17(100)$ & $16(94)$ & - & (29) \\
\hline Voorhees et al & 2017 & $2(1-9)$ & $25(78)$ & $29(91)$ & - & $(27)$ \\
\hline Weber et al & 2012 & $4(1-14)$ & - & $\begin{array}{l}\mathrm{T}: 24(70) \\
\mathrm{R}: 19(56)\end{array}$ & - & (31) \\
\hline Dimopoulos et al & 2013 & $2(1-3)$ & $79(25)$ & $192(61)$ & - & (16) \\
\hline Badros et al & 2009 & $7(3-13)$ & $19(82.6)$ & $\begin{array}{l}\text { R: } 17(73.9) \\
\text { T: } 23(100)\end{array}$ & - & (32) \\
\hline
\end{tabular}

C, Ricolinostat

\begin{tabular}{|c|c|c|c|c|c|c|}
\hline \multirow[b]{2}{*}{ Study } & \multirow[b]{2}{*}{ Year } & \multirow{2}{*}{$\begin{array}{c}\text { Median number of } \\
\text { prior therapies (range) }\end{array}$} & \multicolumn{2}{|c|}{ Prior regimens } & \multirow{2}{*}{$\begin{array}{c}\text { PIs and } \\
\text { iMIDs, n (\%) }\end{array}$} & \multirow[b]{2}{*}{ (Refs.) } \\
\hline & & & PIs, n (\%) & iMIDs, n (\%) & & \\
\hline \multirow[t]{2}{*}{ Vogl et al } & 2017 & $5(2-13)$ & V: 36 (63) & $\mathrm{T}: 12(21)$ & - & $(21)$ \\
\hline & & & $\mathrm{K}: 17$ (30) & R: 38 (67) & & \\
\hline \multirow[t]{2}{*}{ Yee et al } & 2016 & $2(1-3)$ & $11(29)$ & R: 12 (32) & - & (28) \\
\hline & & & & $\mathrm{T}: 4$ (11) & & \\
\hline
\end{tabular}

PIs, Prior regimens containing proteasome inhibitors; iMIDs, Prior regimens containing immunomodulatory drugs; T, Thalidomide; R, lenalidomide; V, bortezomib; K, carfilzomib; Pom, pomalidomide; -, no data available. 
Table III. Response to treatment.

A, Panobinostat

\begin{tabular}{|c|c|c|c|c|c|c|c|}
\hline Study & Year & ORR, n (\%) & $\mathrm{CR}, \mathrm{n}(\%)$ & VGPR, n (\%) & $\mathrm{PR}, \mathrm{n}(\%)$ & M-PFS, months & (Refs.) \\
\hline Isoda et al & 2018 & $6(60)$ & $0(0)$ & $2(20)$ & $4(40)$ & 11.5 & $(26)$ \\
\hline Popat et al & 2016 & $42(91)$ & $3(7)$ & $21(46)$ & $21(46)$ & 15.6 & $(22)$ \\
\hline San-Miguel et al & 2013 & $32(51.6)$ & $2(3.2)$ & $6(9.7)$ & $22(35.5)$ & - & (30) \\
\hline Offidani et al & 2012 & $5(42.0)$ & $0(0)$ & $1(8)$ & $4(33.5)$ & 8.1 & (20) \\
\hline Berdeja et al & 2015 & $28(67)$ & - & $14(33)$ & $14(33)$ & 7.7 & (23) \\
\hline Berenson et al & 2014 & $3(7.5)$ & $0(0)$ & $2(5)$ & $1(2.5)$ & - & (24) \\
\hline Richardson et al & 2013 & $19(34.5)$ & $0(0)$ & $3(5.5)$ & $18(32.7)$ & 5.4 & $(25)$ \\
\hline Wolf et al & 2012 & - & - & - & $1(2.6)$ & - & (19) \\
\hline Baertsch et al & 2018 & $7(33)$ & $0(0)$ & $2(9.5)$ & $5(23.8)$ & 3.5 & (15) \\
\hline San-Miguel et al & 2014 & $235(60.7)$ & $42(11)$ & - & $128(33)$ & 12.0 & (11) \\
\hline Chari et al & 2017 & $11(41)$ & $2(7.4)$ & $4(14.8)$ & $5(18.5)$ & 7.1 & (18) \\
\hline
\end{tabular}

B, Vorinostat

\begin{tabular}{|c|c|c|c|c|c|c|c|}
\hline Study & Year & ORR $(\%)$ & CR (\%) & VGPR (\%) & PR (\%) & M-PFS, months & (Refs.) \\
\hline Sanchez et al & 2016 & $6(24)$ & $0(0)$ & - & $6(24)$ & 5.3 & (17) \\
\hline Vesole et al & 2015 & $9(53)$ & - & $2(12)$ & $7(41)$ & 12 & (29) \\
\hline Voorhees et al & 2017 & $20(65)$ & $2(6)$ & $7(23)$ & $11(35)$ & 13.9 & $(27)$ \\
\hline Weber et al & 2012 & $9(27)$ & $0(0)$ & - & $9(27)$ & - & (31) \\
\hline Dimopoulos et al & 2013 & $177(56.2)$ & $25(7.9)$ & - & $152(48.3)$ & 7.6 & (16) \\
\hline Badros et al & 2009 & $9(42)$ & - & $2(9.5)$ & $7(33.3)$ & - & (32) \\
\hline
\end{tabular}

C, Ricolinostat

\begin{tabular}{lcccccc}
\hline Study & Year & ORR $(\%)$ & CR $(\%)$ & VGPR (\%) & PR (\%) & M-PFS, months \\
\hline Vogl et al & 2017 & $29(29)$ & - & $7(7)$ & $21(21)$ & - \\
Yee et al & 2016 & $21(55)$ & $2(5)$ & $7(18)$ & $10(26)$ & 20.7 \\
\hline
\end{tabular}

ORR, overall response rate; CR, complete response; VGPR, very good partial response; M-PFS, median progression-free survival; -, no data available.

panobinostat-containing regimen was the most effective treatment among these three drugs according to the ORR. Forest plots are presented in Fig. 2.

Response of bortezomib and lenalidomide-refractory patients to HDACi treatment. A subgroup analysis was subsequently conducted to evaluate the effectiveness of HDACis in bortezomib-refractory and lenalidomide-refractory patients. ORR was 0.32 (95\% CI, 0.24-0.40; $\mathrm{I}^{2}, 75.2 \%$; P=0.001) for bortezomib-refractory patients, and 0.43 (95\% CI, 0.30-0.55; $\left.\mathrm{I}^{2}, 68.0 \% ; \mathrm{P}=0.025\right)$ for lenalidomide-refractory patients, suggesting that HDACis were better for the lenalidomide-refractory MM patients. The results are presented in Fig. 3.

Toxicity. An overview of the adverse events is presented in Table IV. Analysis of the pooled data was performed to evaluate the incidence rate of grade 3 and 4 adverse events in all included patients treated with HDACis. The most common hematological adverse events were anemia with an incidence rate of 0.13 (95\% CI, 0.11-0.15; P<0.001; Fig. 4), neutropenia (0.26; $95 \%$ CI, 0.24-0.28; $\mathrm{P}<0.001$; Fig. 5) and thrombocytopenia (0.37; 95\% CI, 0.34-0.39; P<0.001; Fig. 6). Anemia, neutropenia and thrombocytopenia were observed at similar frequencies among panobinostat- and vorinostat-treated patients; however, ricolinostat-treated patients were affected by neutropenia more frequently than patients with anemia or thrombocytopenia. The most frequent non-hematological adverse events included fatigue/asthenia (0.18; 95\% CI; 0.16-0.20; P<0.001; Fig. 7), diarrhea (0.16; 95\% CI; 0.14-0.18; $\mathrm{P}<0.001$; Fig. 8), and nausea (0.06; 95\% CI; 0.05-0.07; P<0.001; Fig. 9).

\section{Discussion}

The recommended dose of each of the three drugs was summarized to provide a reference for future clinical practices. In the included studies, the dosages of panobinostat ranged from 10 


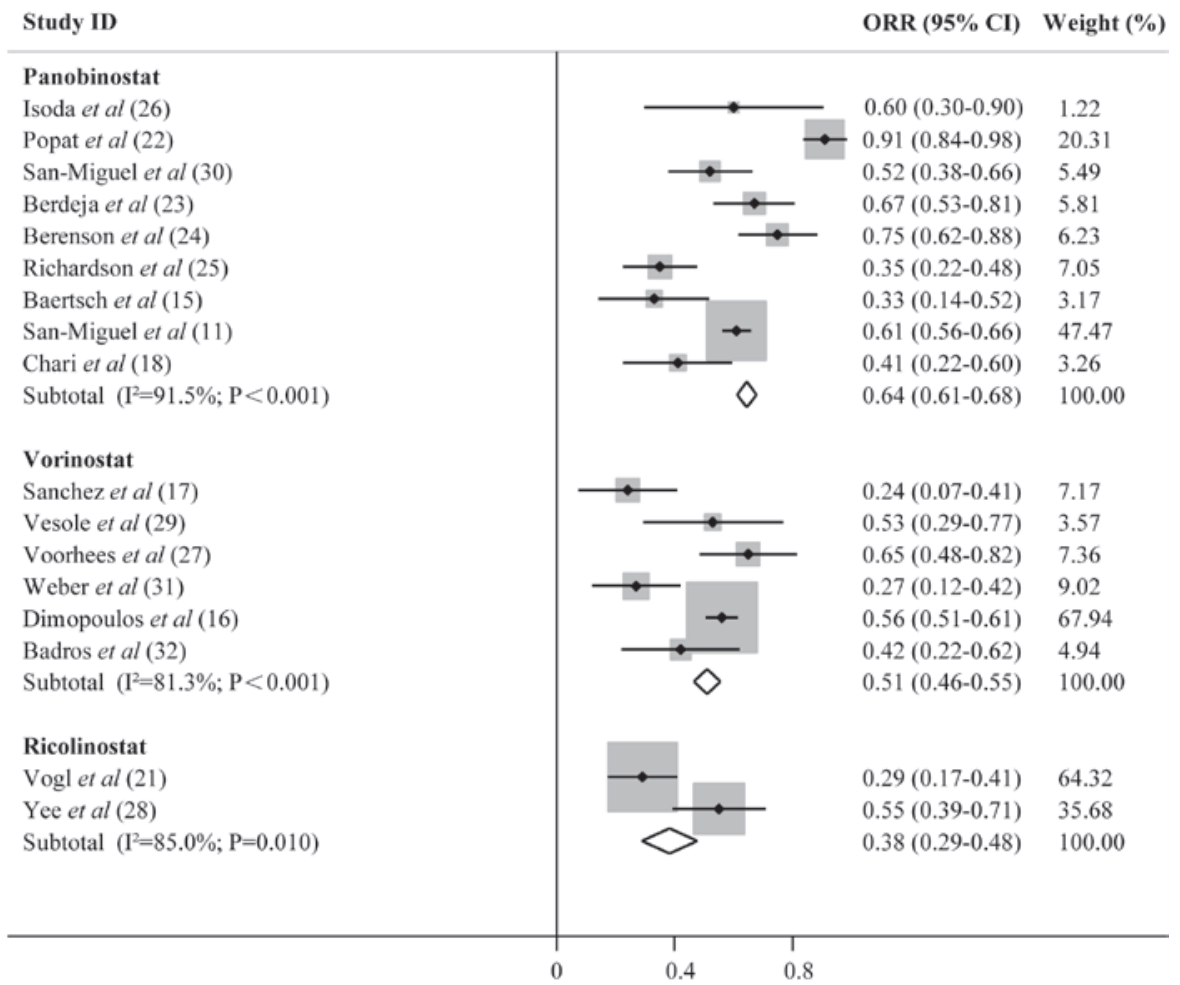

Figure 2. Overall response rate based on pooled data, and on treatment with panobinostat, ricolinostat and vorinostat in patients with relapsed/refractory multiple myeloma. The grey boxes indicate patient weight (\%) and diamonds indicate a combination of the effect sizes in the subgroup.

\begin{tabular}{|c|c|c|c|}
\hline Study ID & & $\begin{array}{l}\text { Incidence Rate } \\
(95 \% \mathrm{CI})\end{array}$ & $\begin{array}{l}\text { Weight } \\
(\%)\end{array}$ \\
\hline \multicolumn{4}{|l|}{ Bortezomib-refractory } \\
\hline Berdeja et al (23) & & $0.67(0.43-0.91)$ & 11.63 \\
\hline Richardson et al (25) & $\longrightarrow$ & $0.38(0.23-0.53)$ & 29.09 \\
\hline Voorhees et al (27) & & $0.45(0.16-0.74)$ & 7.62 \\
\hline Weber et al (31) & $\longrightarrow$ & $0.14(-0.12-0.40)$ & 9.96 \\
\hline Badros et al (32) & $\longrightarrow$ & $0.13(-0.01-0.27)$ & 34.85 \\
\hline Yee et al (28) & & $0.50(0.19-0.81)$ & 6.85 \\
\hline Subtotal $\left(I^{2}=75.2 \% ; P=0.001\right)$ & & $0.32(0.24-0.40)$ & 100.00 \\
\hline \multicolumn{4}{|l|}{ Lenalidomide-refractory } \\
\hline Berdeja et al (23) & & $0.75(0.51-0.99)$ & 25.54 \\
\hline Chari et al (18) & $\rightarrow$ & $0.36(0.16-0.56)$ & 38.10 \\
\hline Sanchez et al (17) & & $0.33(-0.05-0.71)$ & 10.83 \\
\hline Yee et al (28) & $\rightarrow$ & $0.25(0.01-0.49)$ & 25.54 \\
\hline Subtotal $\left(I^{2}=68.0 \% ; P=0.025\right)$ & & $0.43(0.30-0.55)$ & 100.00 \\
\hline
\end{tabular}

Figure 3. Overall response rate of patients with bortezomib-refractory and lenalidomide-refractory multiple myeloma treated with panobinostat, ricolinostat or vorinostat.

to $30 \mathrm{mg}$, and the maximum tolerated dose (MTD) was $20 \mathrm{mg}$, except for in a phase II clinical trial in which it was combined with melphalan, prednisone and thalidomide (20). In that study, the MTD was not determined due to the high rate of dose-limiting toxicities at doses of 10 and $15 \mathrm{mg}$ (20). Additionally, the MTD was established as $30 \mathrm{mg}$ when combined with carfilzomib (23).
Vorinostat inhibited class I, II and IV of HDACs at doses of 100-500 mg in the selected studies, where the MTD was established at $400 \mathrm{mg}$. However, the MTD of vorinostat was not established in studies where it was combined with carfilzomib, lenalidomide and dexamethasone, or co-administered with bortezomib $(29,31)$. In the two studies that included ricolinostat, 
Table IV. HDACi treatment related grade 3 and 4 adverse events.

\begin{tabular}{|c|c|c|c|c|c|c|c|c|}
\hline \multirow[b]{2}{*}{ Study } & \multirow[b]{2}{*}{ Year } & \multicolumn{3}{|c|}{ Hematological } & \multicolumn{3}{|c|}{ Non-hematological } & \multirow[b]{2}{*}{ (Refs.) } \\
\hline & & $\begin{array}{l}\text { Anemia, } \\
\mathrm{n}(\%)\end{array}$ & $\begin{array}{l}\text { Neutropenia, } \\
\mathrm{n}(\%)\end{array}$ & $\begin{array}{c}\text { Thrombocytopenia, } \\
\text { n (\%) }\end{array}$ & $\begin{array}{c}\text { Fatigue/Asthenia, } \\
\mathrm{n}(\%)\end{array}$ & $\begin{array}{l}\text { Diarrhea, } \\
\mathrm{n}(\%)\end{array}$ & $\begin{array}{l}\text { Nausea, } \\
\mathrm{n}(\%)\end{array}$ & \\
\hline Isoda et al & 2018 & - & - & - & $2(20)$ & $2(20)$ & $1(10)$ & (26) \\
\hline Popat et al & 2016 & $3(5)$ & $15(26)$ & $8(14)$ & - & - & $0(0)$ & $(22)$ \\
\hline San-Miguel et al & 2013 & $11(17.7)$ & $37(59.7)$ & $50(80.6)$ & $7(11.3)$ & $10(16.1)$ & $1(1.6)$ & $(30)$ \\
\hline Offidani et al & 2012 & $2(17)$ & $8(66)$ & $5(42)$ & - & - & - & $(20)$ \\
\hline Berdeja et al & 2015 & $4(9)$ & $9(21)$ & $17(38)$ & $5(11)$ & $3(7)$ & $2(5)$ & $(23)$ \\
\hline Berenson et al & 2014 & $21(52.5)$ & $30(75)$ & $29(72.5)$ & $23(57.5)$ & $11(27.5)$ & $22(55)$ & $(24)$ \\
\hline Richardson et al & 2013 & $8(14.5)$ & $8(14.5)$ & $35(63.6)$ & $11(20)$ & $111(20)$ & $3(5.5)$ & $(25)$ \\
\hline Wolf et al & 2012 & $13(34.2)$ & $13(34.2)$ & $15(39.5)$ & $18(47.4)$ & $16(42.1)$ & $21(55.3)$ & (19) \\
\hline Baertsch et al & 2018 & - & - & $17(85)$ & $4(17)$ & $0(0)$ & - & $(15)$ \\
\hline San-Miguel et al & 2014 & - & - & - & $91(24)$ & $97(25)$ & $21(6)$ & $(11)$ \\
\hline Chari et al & 2017 & $2(5)$ & $19(59)$ & $10(31)$ & $4(12.5)$ & $3(9.4)$ & - & (18) \\
\hline Sanchez et al & 2016 & $5(20)$ & $12(48)$ & $8(32)$ & $2(8)$ & $1(4)$ & $1(4)$ & $(17)$ \\
\hline Vesole et al & 2015 & $7(41)$ & $9(53)$ & $9(53)$ & $1(6)$ & $0(0)$ & - & (29) \\
\hline Voorhees et al & 2017 & $0(0)$ & $12(37.5)$ & $15(47)$ & $5(16)$ & $6(19)$ & $3(9)$ & (27) \\
\hline Weber et al & 2012 & $0(0)$ & $3(9)$ & $14(41)$ & $7(21)$ & $3(9)$ & $3(9)$ & (31) \\
\hline Dimopoulos et al & 2013 & $47(15)$ & 59 (19) & $74(23)$ & $50(16)$ & $51(16)$ & $24(8)$ & (16) \\
\hline Badros et al & 2009 & - & - & - & $11(47.8)$ & $5(21.7)$ & - & (32) \\
\hline Vogl et al & 2017 & $11(19)$ & $2(4)$ & $21(37)$ & $4(7)$ & $3(5)$ & $1(2)$ & (21) \\
\hline Yee et al & 2016 & $2(5)$ & $10(26)$ & $2(5)$ & 7 (18) & $2(5)$ & $1(3)$ & (28) \\
\hline
\end{tabular}

-, no data available.

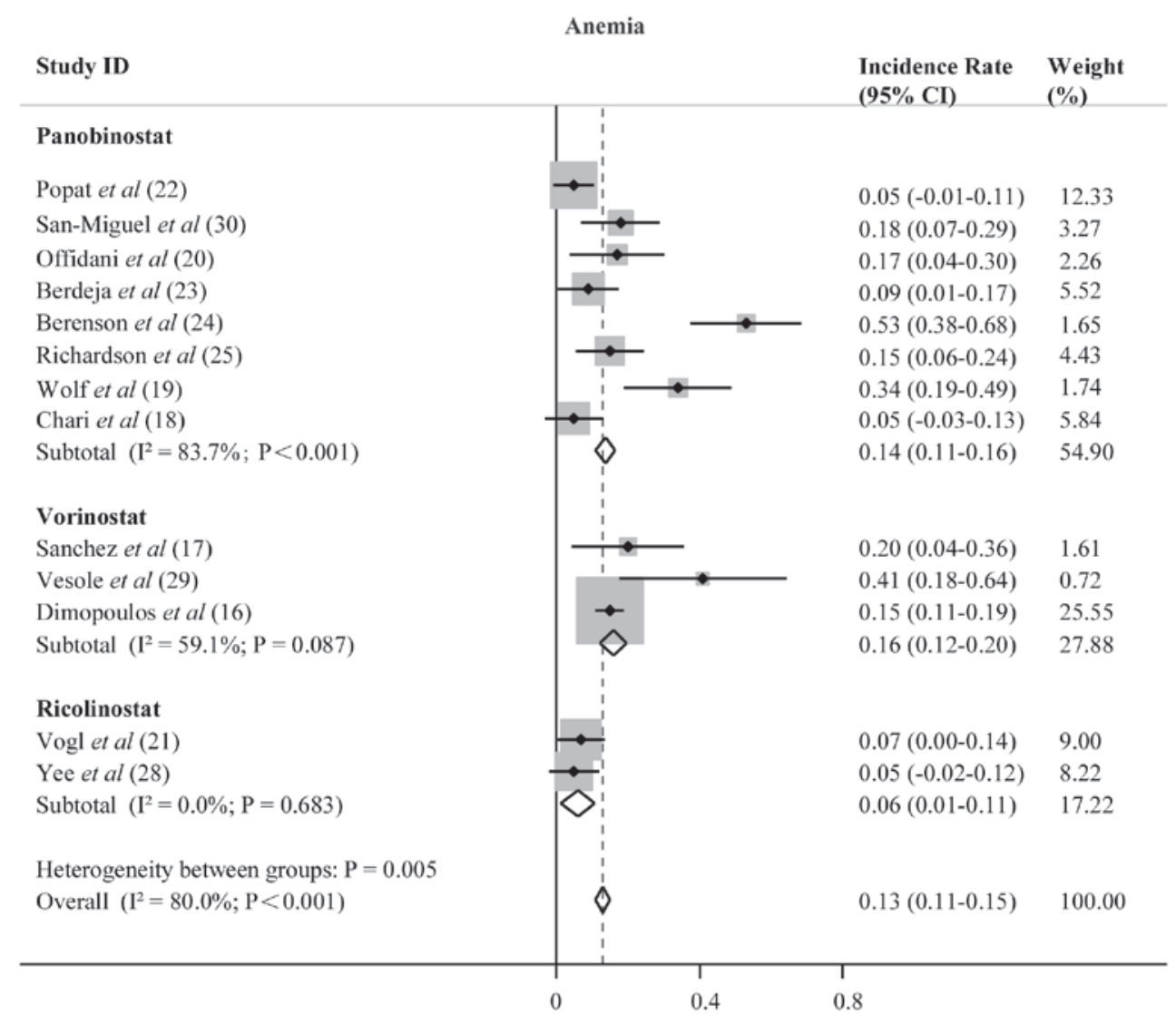

Figure 4 . The incidence rate of grade 3 and 4 adverse event anemia. The vertical dashed line indicated overall incidence rate. 


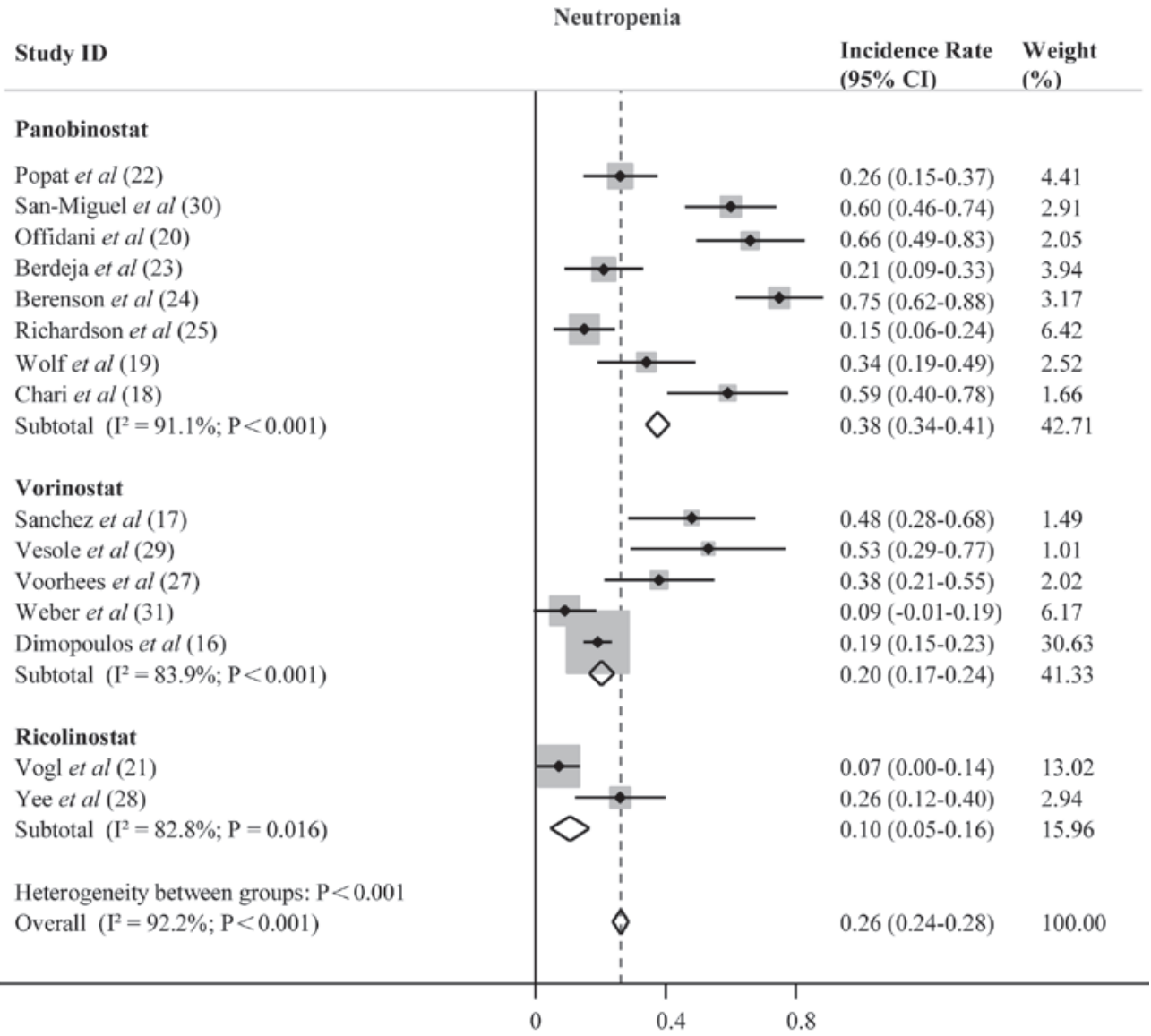

Figure 5. The incidence rate of grade 3 and 4 adverse event neutropenia. The vertical dashed line indicated overall incidence rate.

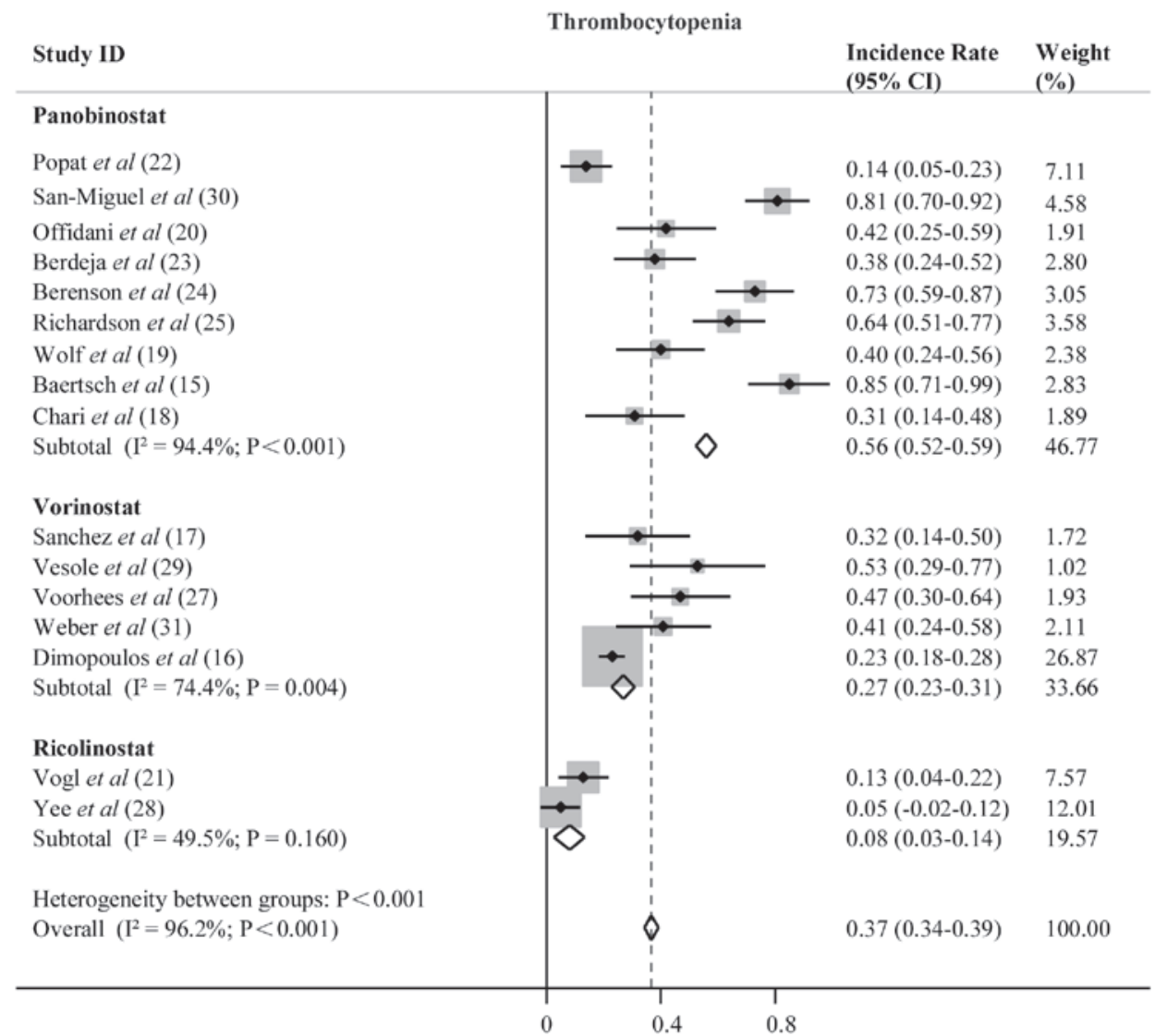

Figure 6. The incidence rate of grade 3 and 4 adverse event thrombocytopenia. The vertical dashed line indicated overall incidence rate. 


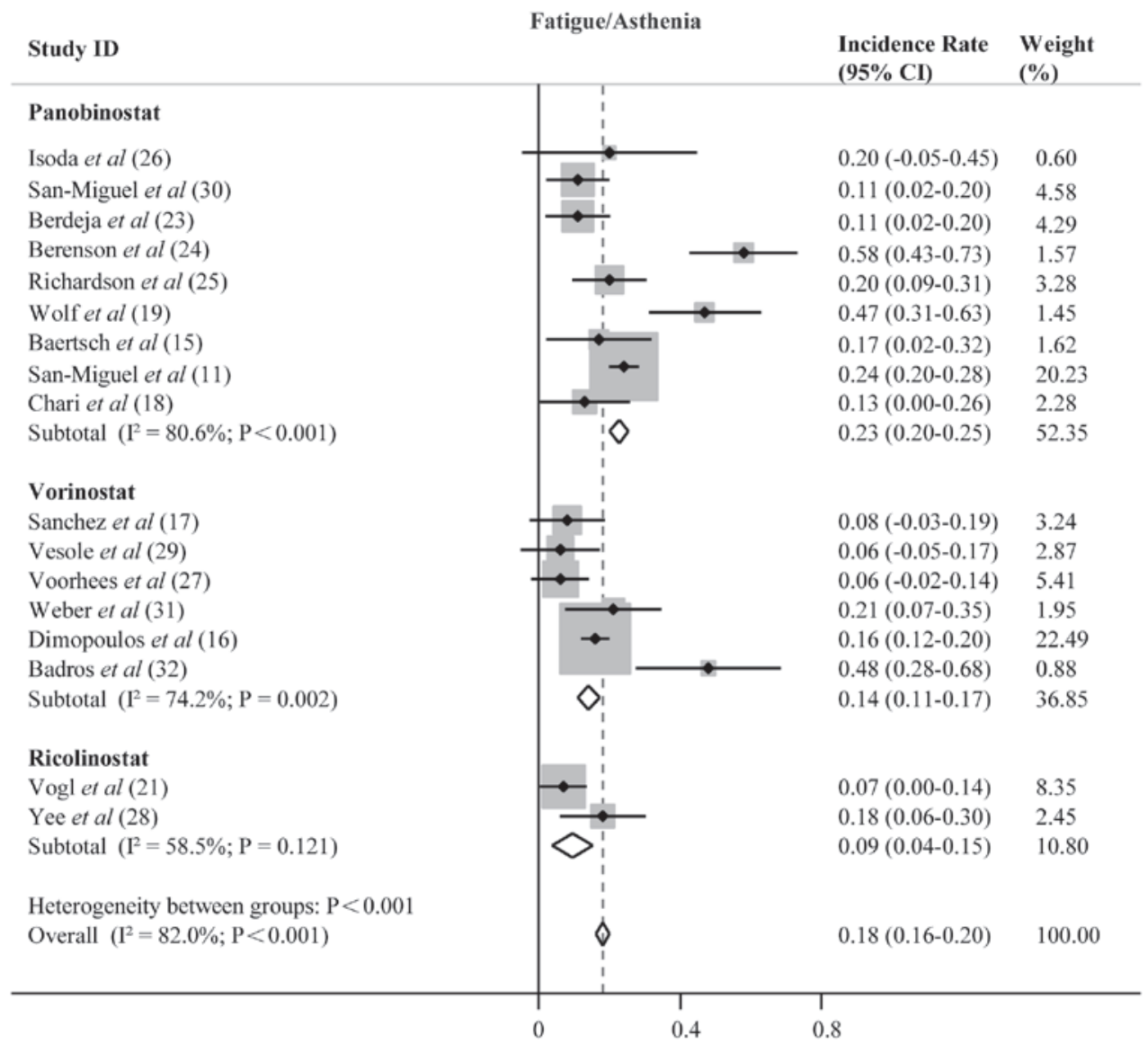

Figure 7. The incidence rate of grade 3 and 4 adverse event fatigue/asthenia. The vertical dashed line indicated overall incidence rate.

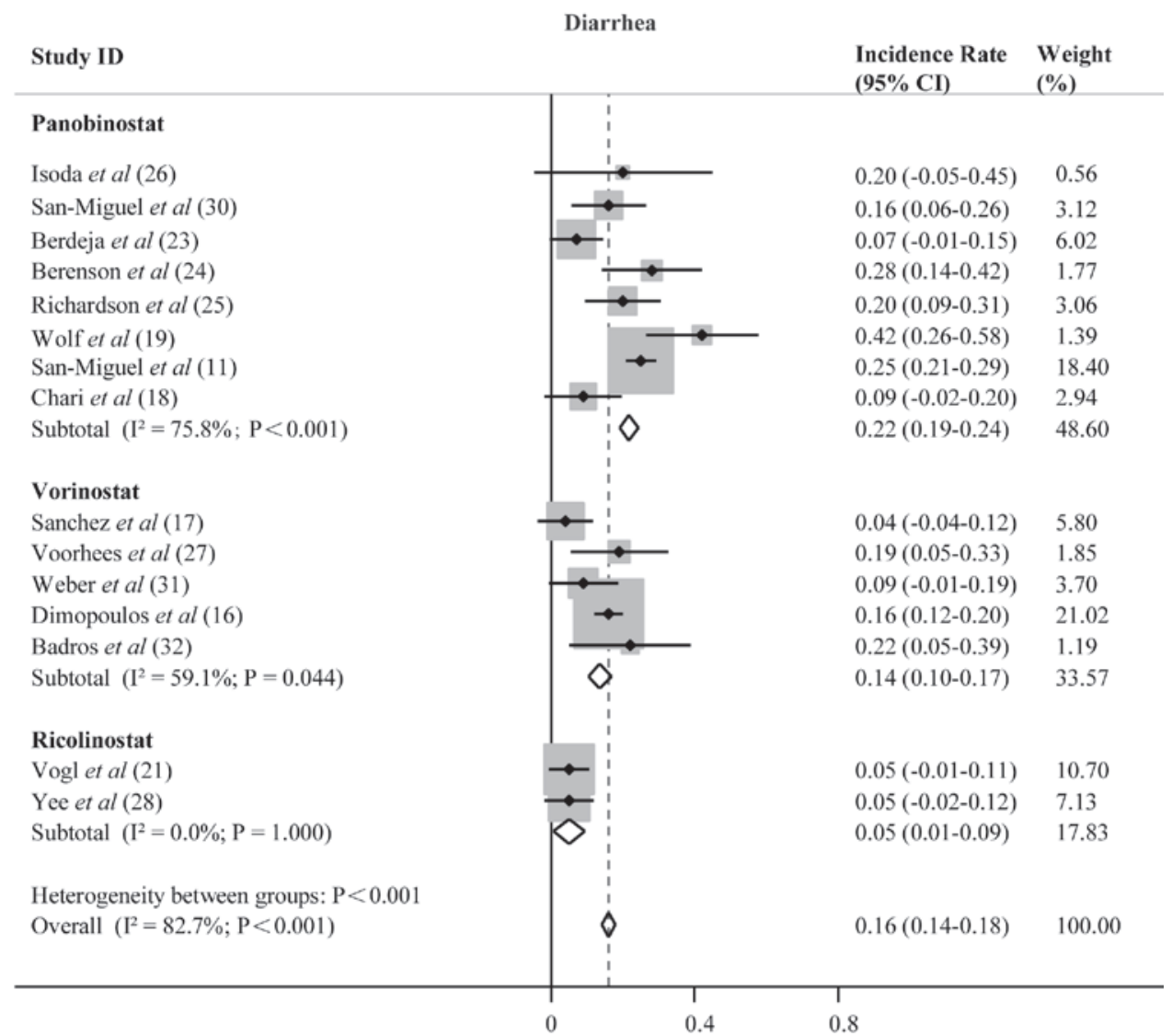

Figure 8. The incidence rate of grade 3 and 4 adverse event diarrhea. The vertical dashed line indicated overall incidence rate. 


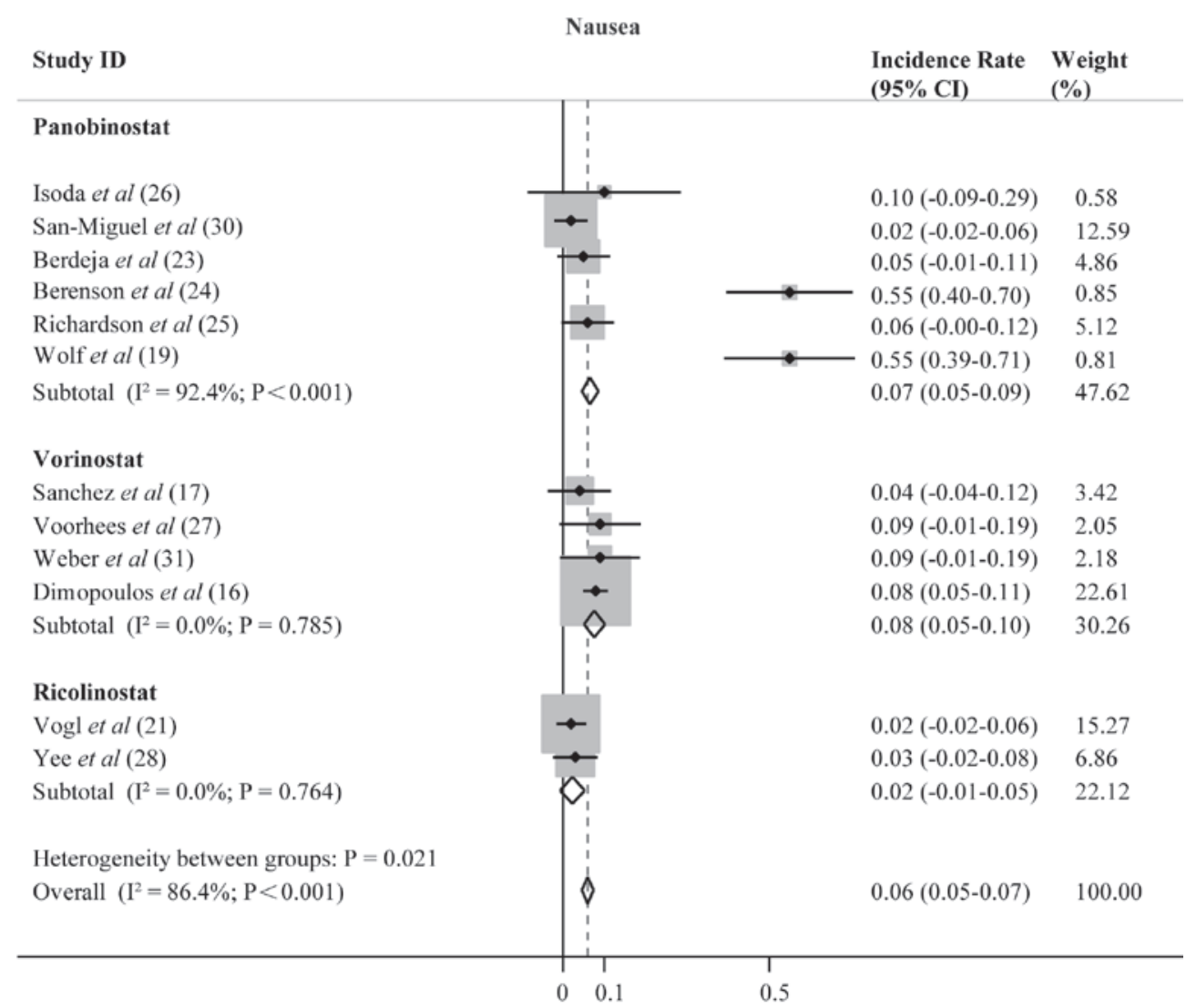

Figure 9. The incidence rate of grade 3 and 4 adverse event nausea. The vertical dashed line indicated overall incidence rate.

patients were treated in cohorts with doses of 40-240 mg. Although the MTD of ricolinostat was not established, a recommended phase II dose was defined at $160 \mathrm{mg}$ (28). Overall, the data suggested that the doses used for the HDAC inhibitors varied based on different combination regimens.

The meta-analysis results indicated that panobinostat was more effective and safer than vorinostat and ricolinostat. In the subgroup analysis, the highest ORR of 0.64 was observed in RRMM patients treated with panobinostat. This was followed by ORRs of 0.51 and 0.38 in RRMM patients treated with vorinostat and ricolinostat, respectively. Panobinostat is a non-selective HDACi, targeting class I, II and IV HDACs. A study by Wolf et al (19) found that only one out of 38 patients achieved a partial response (PR) with panobinostat monotherapy. The outcome indicated that panobinostat alone showed little clinical efficacy in the treatment of RRMM. However, there was a significant improvement in clinical efficacy when panobinostat was used in combination with proteasome inhibitors (PIs) or immunomodulatory drugs (iMIDs) for RRMM. Importantly, a study by Popat et al (22) demonstrated that panobinostat in combination with bortezomib, thalidomide and dexamethasone generated an ORR of 0.91 (95\% CI, 0.84-0.98), and lower rates of hematological adverse events, including neutropenia and thrombocytopenia in comparison to other studies. These results suggest that multidrug combinations may be more effective treatment strategies for RRMM. There were only a few studies with small sample sizes included in the ricolinostat-treated group for the pooled analysis $(21,28)$. Ricolinostat, a selective inhibitor of HDAC6, preliminarily showed a weaker anti-MM effect than the other two drugs in the present study, thereby implying that selective HDACis are less effective than non selective HDACis (pan-HDACis).

In the present study, subgroup analysis also demonstrated that lenalidomide-refractory MM patients had a better ORR than bortezomib-refractory MM patients after treatment with HDACi-containing regimens. It was hypothesized that this may be due to PI-refractory patients not being responsive to HDAC inhibitors alone, but being responsive to the combined effect of PIs and HDACis.

In addition, the safety of the three drugs was evaluated by analyzing the incidence of adverse events. Panobinostat and vorinostat showed a similar trend of overall incidence of hematological adverse events of thrombocytopenia, neutropenia and anemia, and non-hematological adverse events of fatigue/asthenia, diarrhea and nausea. By contrast, the most common hematological adverse event for ricolinostat was neutropenia. The difference in adverse event profiles of HDAC inhibitors should be carefully considered by clinicians in the clinical management of patients with RRMM.

There were also several limitations in the present meta analyses which should be considered. First, in addition to 3 studies from Japan, Italy and Germany, the remaining 16 studies included in the current analysis were from the United States, suggesting that the outcome maybe be biased for the American population. Second, even with using a random effects model in statistical analysis, the data were still confounded by a high degree of heterogeneity. This was probably due to the numerous combination regimens administered in different studies. Third, most of the studies included in the 
present analysis were single-arm clinical trials. There were only two phase III trials $(11,16)$ that provided OS and PFS data, which are the main indicators used to evaluate drug efficacy in oncology clinical trials.

In conclusion, panobinostat-containing regimens were effective in treating patients with RRMM, but ricolinostat and vorinostat-containing regimens did not yield satisfactory results for patients with RRMM. Additionally, lenalidomide-refractory patients may benefit from HDACi treatment more than patients with bortezomib-refractory. However, a longer follow-up period is required to investigate crucial study endpoints of PFS and OS.

\section{Acknowledgements}

Not applicable.

\section{Funding}

No funding was received.

\section{Availability of data and materials}

The datasets used and/or analyzed during the present study are available from the corresponding author on reasonable request.

\section{Authors' contributions}

$\mathrm{XG}$ and LS directed the study and XG wrote the manuscript. $\mathrm{XG}$ and XL extracted data. JL conducted the statistical analysis of data. LS critically revised the article for important intellectual content. All authors read and approved the final manuscript.

\section{Ethics approval and consent to participate}

Not applicable.

\section{Patient consent for publication}

Not applicable.

\section{Competing interests}

The authors declare that they have no competing interests.

\section{References}

1. Siegel RL, Miller KD and Jemal A: Cancer statistics, 2017. CA Cancer J Clin 67: 7-30, 2017.

2. Rajkumar SV: Multiple myeloma: 2016 update on diagnosis, risk-stratification, and management. Am J Hematol 91: 719-734, 2016.

3. Rajkumar SV and Kumar S: Multiple myeloma: Diagnosis and treatment. Mayo Clin Proc 91: 101-119, 2016.

4. Kumar SK, Rajkumar SV, Dispenzieri A, Lacy MQ, Hayman SR, Buadi FK, Zeldenrust SR, Dingli D, Russell SJ, Lust JA, et al: Improved survival in multiple myeloma and the impact of novel therapies. Blood 111: 2516-2520, 2008.

5. Chim CS, Kumar SK, Orlowski RZ, Cook G, Richardson PG, Gertz MA, Giralt S, Mateos MV, Leleu X and Anderson KC: Management of relapsed and refractory multiple myeloma: Nove agents, antibodies, immunotherapies and beyond. Leukemia 32: 252-262, 2018
6. Mann BS, Johnson JR, Cohen MH, Justice R and Pazdur R: FDA approval summary: Vorinostat for treatment of advanced primary cutaneous T-cell lymphoma. Oncologist 12: 1247-1252, 2007.

7. Mithraprabhu S, Kalff A, Chow A, Khong T and Spencer A Dysregulated class I histone deacetylases are indicators of poor prognosis in multiple myeloma. Epigenetics 9: 1511-1520, 2014.

8. Catley L, Weisberg E, Kiziltepe T, Tai YT, Hideshima T, Neri P, Tassone P, Atadja P, Chauhan D, Munshi NC and Anderson KC: Aggresome induction by proteasome inhibitor bortezomib and alpha-tubulin hyperacetylation by tubulin deacetylase (TDAC) inhibitor LBH589 are synergistic in myeloma cells. Blood 108: 3441-3449, 2006.

9. Simms-Waldrip T, Rodriguez-Gonzalez A, Lin T, Ikeda AK, $\mathrm{Fu} \mathrm{C}$ and Sakamoto KM: The aggresome pathway as a target for therapy in hematologic malignancies. Mol Genet Metab 94: 283-286, 2008

10. Hideshima T, Bradner JE, Wong J, Chauhan D, Richardson P, Schreiber SL and Anderson KC: Small-molecule inhibition of proteasome and aggresome function induces synergistic antitumor activity in multiple myeloma. Proc NatI Acad Sci USA 102: 8567-8572, 2005.

11. San-Miguel JF, Hungria VT, Yoon SS, Beksac M, Dimopoulos MA, Elghandour A, Jedrzejczak WW, Günther A, Nakorn TN, Siritanaratkul N, et al: Panobinostat plus bortezomib and dexamethasone versus placebo plus bortezomib and dexamethasone in patients with relapsed or relapsed and refractory multiple myeloma: A multicentre, randomised, double-blind phase 3 trial. Lancet Oncol 15: 1195-1206, 2014.

12. Harada T, Hideshima T and Anderson KC: Histone deacetylase inhibitors in multiple myeloma: From bench to bedside. Int J Hematol 104: 300-309, 2016.

13. Trotti A, Colevas AD, Setser A, Rusch V, Jaques D, Budach V, Langer C, Murphy B, Cumberlin R, Coleman CN and Rubin P: CTCAE v3.0: Development of a comprehensive grading system for the adverse effects of cancer treatment. Semin Radiat Oncol 13: 176-181, 2003.

14. Moher D, Liberati A, Tetzlaff J and Altman DG: Preferred reporting items for systematic reviews and meta-analyses: The PRISMA statement. PLoS Med 6: e1000097, 2009.

15. Baertsch MA, Hillengass J, Blocka J, Schönland S, Hegenbart U, Goldschmidt $\mathrm{H}$ and Raab MS: Efficacy and tolerability of the histone deacetylase inhibitor panobinostat in clinical practice. Hematol Oncol 36: 210-216, 2018.

16. Dimopoulos M, Siegel DS, Lonial S, Qi J, Hajek R, Facon T, Rosinol L, Williams C, Blacklock $\mathrm{H}$, Goldschmidt $\mathrm{H}$, et al: Vorinostat or placebo in combination with bortezomib in patients with multiple myeloma (VANTAGE 088): A multicentre, randomised, double-blind study. Lancet Oncol 14: 1129-1140, 2013.

17. Sanchez L, Vesole DH, Richter JR, Biran N, Bilotti E, McBride L, Anand P, Ivanovski K and Siegel DS: A phase IIb trial of vorinostat in combination with lenalidomide and dexamethasone in patients with multiple myeloma refractory to previous lenalidomide-containing regimens. Br J Haematol 176: 440-447, 2017.

18. Chari A, Cho HJ, Dhadwal A, Morgan G, La L, Zarychta K, Catamero D, Florendo E, Stevens N, Verina D, et al: A phase 2 study of panobinostat with lenalidomide and weekly dexamethasone in myeloma. Blood Adv 1: 1575-1583, 2017.

19. Wolf JL, Siegel D, Goldschmidt H, Hazell K, Bourquelot PM, Bengoudifa BR, Matous J, Vij R, de Magalhaes-Silverman M, Abonour R, et al: Phase II trial of the pan-deacetylase inhibitor panobinostat as a single agent in advanced relapsed/refractory multiple myeloma. Leuk Lymphoma 53: 1820-1823, 2012.

20. Offidani M, Polloni C, Cavallo F, Liberati AM, Ballanti S, Pulini S, Catarini M, Alesiani F, Corvatta L, Gentili S, et al: Phase II study of melphalan, thalidomide and prednisone combined with oral panobinostat in patients with relapsed/refractory multiple myeloma. Leuk Lymphoma 53: 1722-1727, 2012.

21. Vogl DT, Raje N, Jagannath S, Richardson P, Hari P, Orlowski R, Supko JG, Tamang D, Yang M, Jones SS, et al: Ricolinostat, the first selective histone deacetylase 6 inhibitor, in combination with bortezomib and dexamethasone for relapsed or refractory multiple myeloma. Clin Cancer Res 23: 3307-3315, 2017.

22. Popat R, Brown SR, Flanagan L, Hall A, Gregory W, Kishore B, Streetly M, Oakervee H, Yong K, Cook G, et al: Bortezomib, thalidomide, dexamethasone, and panobinostat for patients with relapsed multiple myeloma (MUK-six): A multicentre, open-label, phase 1/2 trial. Lancet Haematol 3: e572-e580, 2016.

23. Berdeja JG,Hart LL, Mace JR, Arrowsmith ER, Essell JH, Owera RS, Hainsworth JD and Flinn IW: Phase I/II study of the combination of panobinostat and carfilzomib in patients with relapsed/refractory multiple myeloma. Haematologica 100: 670-676, 2015. 
24. Berenson JR, Hilger JD, Yellin O, Boccia RV, Matous J, Dressler K, Ghazal HH, Jamshed S, Kingsley EC, Harb WA, et al: A phase $1 / 2$ study of oral panobinostat combined with melphalan for patients with relapsed or refractory multiple myeloma. Ann Hematol 93: 89-98, 2014.

25. Richardson PG, Schlossman RL, Alsina M, Weber DM, Coutre SE, Gasparetto C, Mukhopadhyay S, Ondovik MS, Khan M, Paley CS and Lonial S: PANOR AMA 2: Panobinostat in combination with bortezomib and dexamethasone in patients with relapsed and bortezomib-refractory myeloma. Blood 122: 2331-2337, 2013.

26. Isoda A, Ishikawa T, Miyazawa Y, Mihara M, Matsumoto M and Sawamura M: Intra-patient dose escalation of panobinostat in patients with relapsed/refractory multiple myeloma. Leuk Lymphoma 59: 1277-1278, 2018.

27. Voorhees PM, Gasparetto C, Moore DT, Winans D, Orlowski RZ and Hurd DD: Final results of a Phase 1 study of vorinostat, pegylated liposomal doxorubicin, and bortezomib in relapsed or refractory multiple myeloma. Clin Lymphoma, Myeloma Leuk 17: 424-432, 2017

28. Yee AJ, Bensinger WI, Supko JG, Voorhees PM, Berdeja JG, Richardson PG, Libby EN, Wallace EE, Birrer NE, Burke JN, et al: Ricolinostat plus lenalidomide, and dexamethasone in relapsed or refractory multiple myeloma: A multicentre phase 1b trial. Lancet Oncol 17: 1569-1578, 2016.
29. Vesole DH, Bilotti E, Richter JR, McNeill A, McBride L, Raucci L, Anand P, Bednarz U, Ivanovski K, Smith J, et al: Phase I study of carfilzomib, lenalidomide, vorinostat, and dexamethasone in patients with relapsed and/or refractory multiple myeloma. Br J Haematol 171: 52-59, 2015.

30. San-Miguel JF, Richardson PG, Gunther A, Sezer O, Siegel D, Bladé J, LeBlanc R, Sutherland H, Sopala M, Mishra KK et al: Phase Ib study of panobinostat and bortezomib in relapsed or relapsed and refractory multiple myeloma. J Clin Oncol 31: 3696-3703, 2013.

31. Weber DM, Graef T, Hussein M, Sobecks RM, Schiller GJ, Lupinacci L, Hardwick JS and Jagannath S: Phase I trial of vorinostat combined with bortezomib for the treatment of relapsing and/or refractory multiple myeloma. Clin Lymphoma Myeloma Leuk 12: 319-324, 2012.

32. Badros A,BurgerAM,PhilipS,Niesvizky R,KollaSS,GoloubevaO, Harris C, Zwiebel J, Wright JJ, Espinoza-Delgado I, et al: Phase I study of vorinostat in combination with bortezomib for relapsed and refractory multiple myeloma. Clin Cancer Res 15: 5250-5257, 2009.

This work is licensed under a Creative Commons Attribution-NonCommercial-NoDerivatives 4.0 International (CC BY-NC-ND 4.0) License. 